\title{
PENERAPAN BALANCED SCORECARD PADA PERUSAHAAN JASA DI INDONESIA
}

\author{
Markus Djohan Utama \\ Ririn Breliastiti \\ Universitas Bunda Mulia \\ mutama@bundamulia.ac.id
}

\begin{abstract}
Each company must have objectives that must be achieved. The main objective of the company is trying to make a profit as much as possible, where the profit is often used for business development. At this time, the popular method of performance measurement is the Balanced Scorecard. This method has been integrated with various methods of business strategy is expected to improve the company's performance significantly. Balanced Scorecard is a measurement method for measuring the company's performance in the future by considering four perspectives to measure the performance of the company are financial perspective, customer perspective, internal business process, and learning-growth perspective. This study aims to determine the application of Balanced Scorecard according to four perspectives and results of their performance according to the Balanced Scorecard measures for the three service companies under investigation. This research is a descriptive study based on observations carried out at three services company in Indonesia. Research on the application of balanced scorecard will be performed at three selected service companies, namely PT Fast Food Indonesia, PT Graha Layar Prima and PT Kristamedia Primary. Research results that the three companies have a Balanced Scorecard approach is a bit different, but still using the same four perspectives. Determination of the weight and the score is determined by the company taking into account the targets to be achieved for each perspective. The indicators used for each perspective also vary, depending on the target to be achieved, and the types of indicators can also vary. The three companies produce good Balanced Scorecard, which illustrates that the financial and non-financial performance can work in harmony and balance to achieve the goals set.
\end{abstract}

Keywords: Balanced Scorecard

\section{Pendahuluan}

\subsection{Latar Belakang Masalah}

Memasuki abad ke dua puluh satu, persaingan antar perusahaan semakin ketat baik dalam negeri maupun dalam skala internasional. Perusahaan berlomba-lomba untuk menjadi yang terbaik di segala aspek, baik dari sisi produksi, biaya, harga, pelayanan, pemasaran, dan lain-lain. Hal ini menyebabkan perusahaan terus 
melakukan perubahan dan menerapkan banyak inovasi untuk terus dapat mempertahankan eksistensi mereka. Salah satu kunci untuk menghadapi persaingan dan perubahan tersebut adalah dengan meningkatkan kepuasan pelanggan. Untuk mewujudkan kepuasan pelanggan secara terus menerus, perusahaan perlu menentukan strategi yang tepat dalam pengelolaannya. Strategi yang ditentukan akan dijadikan landasan dan kerangka kerja untuk mewujudkan tujuan perusahaan yang telah ditentukan.

Setiap perusahaan tentunya mempunyai tujuan-tujuan yang harus dicapai. Yang menjadi tujuan utama dari perusahaan adalah berusaha untuk mendapatkan profit yang sebesar-besarnya, dimana profit yang didapat seringkali digunakan untuk melakukan pengembangan usaha. Pengembangan usaha perlu dilakukan agar produk yang dihasilkan oleh perusahaan dapat bersaing dengan produk lain. Perusahaan yang mampu bertahan di dalam pasar internasional ini hanyalah perusahaan-perusahaan yang memiliki standar kinerja yang tinggi dan mampu menghasilkan keuntungan dalam jangka panjang.
Oleh karena itu, banyak perusahaan dunia dewasa ini sedang melakukan penyesuaian dalam struktur dan sistem organisasi dengan perubahanperubahan yang terjadi.

Pada saat ini, metode pengukuran kinerja yang popular adalah Balanced Scorecard. Metode ini telah diintegrasikan dengan berbagai metode strategi bisnis yang diharapkan dapat meningkatkan kinerja perusahaan secara signifikan. Balanced Scorecard merupakan suatu metode pengukuran untuk mengukur kinerja perusahaan di masa depan dengan mempertim-bangkan empat perspektif untuk mengukur kinerja perusahaan yaitu: perspektif keuangan, perspektif pelanggan, perspektif proses bisnis internal, dan perspektif pem-belajaranpertumbuhan. Dari ke-empat perspektif tersebut, dapat dilihat bahwa Balanced Scorecard mengukur kinerjanya dengan memperhatikan keseimbangan antara sisi keuangan dan non keuangan, jangka pendek dan jangka panjang serta melibatkan pula faktor internal dan eksternal.

Di Indonesia, penerapan Balanced Scorecard telah mulai digunakan 
terutama perusahaan dengan skala usaha yang besar. Selayaknya strategi, penerapan Balanced Scorecard terkadang merupakan hal yang tidak diungkap secara terbuka. Di sisi lain, Balanced Scorecard merupakan alat managerial yang cukup tangguh untuk dapat mengukur kinerja perusahaan secara komprehensif dan menjadi pedoman bagi perusahaan untuk mencapai visinya. oleh karenanya terdapat kebutuhan dari dunia bisnis untuk melakukan benchmarking atas penerapan Balanced Scorecard pada perusahaan-perusahaan dalam industri yang sejenis.

Penelitian ini bertujuan untuk memberikan pembahasan mengenai penerapan Balanced Scorecard pada perusahaan jasa di Indonesia. Dengan adanya contoh ini diharapkan banyak perusahaan di Indonesia yang akhirnya tertarik dan dapat juga memperoleh manfaat.

\subsection{Batasan Masalah}

Jenis usaha sangatlah beragam. Namun secara umum dapat dikelompokkan dalam tiga katagori yaitu perusahaan jasa, dagang dan manufaktur. Penelitian ini akan membahas khusus pada perusahaan jasa, yaitu jasa makanan dan minuman, jasa hiburan dan jasa penyelenggara pameran.

\subsection{Perumusan Masalah}

a. Bagaimanakah kinerja perusahaan bila diukur dengan menggunakan pers-pektif keuangan?

b. Bagaimanakah kinerja perusahaan bila diukur dengan menggunakan perspektif pelanggan?

c. Bagaimanakah kinerja perusahaan bila diukur dengan menggunakan perspektif proses bisnis internal?

d. Bagaimanakah kinerja perusahaan bila diukur dengan menggunakan perspektif pembelajaran-pertumbuhan?

e. Bagaimanakah kesimpulan dari nilai Balanced Scorecard dari ketiga perusahaan?

\section{Tinjauan Pustaka}

\subsection{Pengertian Akuntansi Mana- jemen}

Menurut Hansen \& Mowen (2009a), Akuntansi manajemen merupakan proses mengiden-tifikasi, mengumpulkan, mengukur, 
mengklasifikasi dan melaporkan informasi yang bermanfaat bagi pengguna internal dalam merencanakan, mengendalikan dan mengambil keputusan. Sedangkan menurut Reeve (2009), Akuntansi Manajemen menggunakan akuntansi keuangan maupun data estimasi untuk membantu manajemen dalam menjalankan aktivitas operasional harian dan merencanakan aktivitas operasional di masa depan.

\subsection{Pengukuran Kinerja}

Wibowo (2013), kinerja merupakan hasil pekerjaan yang mempunyai hubungan yang kuat dengan tujuan strategis organisasi, kepuasan konsumen dan memberikan kontribusi ekonomi. Menurut Hansen \& Mowen (2009b), sistem pengukuran kinerja diturunkan dari visi, misi, strategi, dan tujuan suatu perusahaan. Dalam menetapkan sistem pengukuran kinerja, manajemen puncak memilih serangkaian ukuran-ukuran yang menunjukkan strategi perusahaan. Ukuran-ukuran ini harus diseimbangkan antara ukuran lag dan lead, objektif dan subjektif, keuangan dan non keuangan, serta ukuran eksternal dan internal. Ukuran lag adalah ukuran output, ukuran hasil dari usaha di masa lalu (contoh: profitabilitas pelanggan). Ukuran lead (penggerak kinerja) adalah faktor-faktor yang menggerakkan kinerja masa depan (contoh: jumlah jam pelatihan karyawan). Ukuran objektif adalah ukuran yang bisa langsung dihitung dan diversifikasi (contoh: pangsa pasar), sedangkan ukuran subjektif lebih sulit dihitung dan lebih bersifat praduga (contoh: kemampuan karyawan). Ukuran keuangan adalah ukuran yang dinyatakan dalam istilah moneter, sedangkan ukuran non keuangan menggunakan unit-unit non moneter (contoh: biaya per unit dan jumlah pelanggan yang tidak puas). Ukuran eksternal berkaitan dengan pelanggan dan pemegang saham (contoh: kepuasan pelanggan dan pengembalian atas investasi). Ukuran internal adalah ukuran yang berkaitan dengan proses dan kemampuan yang menciptakan nilai bagi pelanggan dan pemegang saham (contoh: efisiensi proses dan kepuasan karyawan). 


\subsection{Pengertian Balanced Score- card}

Menurut Rangkuti (2013) Balanced Scorecard adalah kartu skor yang digunakan untuk mengukur kinerja dengan memperhatikan keseimbangan antara sisi keuangan dengan nonkeuangan, antara jangka pendek dan jangka panjang serta melibatkan faktor internal dan eksternal.

Menurut Anthony dan Govindarajan (2009) Balanced Scorecard adalah suatu contoh dari sistem ukuran kinerja. Balanced Scorecard memelihara keseimbangan antara ukuran-ukuran strategis yang berbeda dalam suatu usaha mencapai keselarasan cita-cita, sehingga dengan demikian mendorong karyawan untuk bertindak sesuai dengan kepentingan terbaik organisasi.

\subsection{Kelebihan Balanced Score- card}

Menurut Mahmudi (2013), Balanced Scorecard memberikan jawaban terhadap empat pertanyaan dasar:

1. Bagaimanakah pelanggan melihat kita (perspektif pelanggan)?

2. Keunggulan apa yang harus kita miliki (perspektif bisnis internal)?
3. Dapatkah kita terus melakukan perbaikan dan menciptakan nilai (perspektif inovasi dan pembelajaran)?

4. Bagaimanakah kita melihat pemegang saham (perspektif finansial)?

\subsection{Empat Perspektif Balanced Scorecard}

Menurut Suprayitno (2011), Balanced Scorecard menyarankan bahwa kita melihat suatu kinerja organisasi dari empat perspektif berikut:

\section{Learning and Growth}

Perspective. Kategori-kategori yang terdapat dalam perspektif ini teridiri atas kemampuan karyawan; kemampuan sistem informasi; dan motivasi, peberdayaan, serta kesesuaian dengan standard kinerja. Ukuran intinya adalah produktivitas karyawan, yang diukur dari: jumlah output tiap karyawan, tingkat kepuasan karyawan, tinggi rendahnya pengakuan terhadap prestasi karyawan, tingkat keterlibatan karyawan dalam proses pengambilan keputusan, kemudahan akses karyawan terhadap informasi yang me- 
nunjang pekerjaannya, dan tingkat retensi atau penolakan karyawan, yang diukur dari jumlah perputaran (turn over) staf atau karyawan potensial.

\section{Internal-Business-Process}

Perspective. Dalam perspektif internal-business-process, manajer mengenali proses-proses kritis pada yang mana mereka harus unggul jika mereka akan mencapai tujuan-tujuan dari shareholder dan segmen pelanggan yang menjadi target. Sistem pengukuran performa

konvensional berfokus hanya pada monitoring dan peningkatan biaya, mutu, dan waktu yang didasarkan pada proses bisnis yang ada. Secara jelas, pendekatan dari Balanced

Scorecard

memungkinkan per-mintaan untuk performans proses internal untuk menurunkan harapan-haran khusus dari pihak eksternal perusahaan.

3. Customer Perspective. Perspektif Pelanggan ini menggambarkan tampilan perusahaan di mata pelanggan. Hal ini merupakan konsekuensi dari tingkat persaingan usaha yang makin ketat, sehingga perusahaan dituntut memahami kebutuhan pelanggannya (customer driven company) Ukuran utama dari perspektif pelanggan adalah market share, customer acquisition, customer retention, customer satisfaction, dan customer profitability. Kelima buah ukuran ini tidaklah terpisahpisah, melainkan memiliki saling berhubungan.

4. Financial Perspective. Tujuan finansial menyajikan suatu fokus untuk tujuan dan ukuran dalam seluruh perspektif Balanced Scorecard. Setiap ukuran dipilih harus menjadi bagian dari suatu hubungan sebab-akibat yang memuncak dalam peningkatan performans keuangan. Balanced Scorecard harus menguraikan tentang strategi, dimulai dengan tujuan finansial jangka panjang, dan kemudian keterkaitannya terhadap bagian-bagian tindakan yang harus diambil dengan proses finansial, pelanggan, internal proses, dan terakhir karyawan dan sistem untuk mengantarkan performans ekonomis jangka panjang yang diharapkan. 
Walaupun bergantung pada daur hidup industrinya, tujuan strategi perspektif keuangan pada umumnya terkait pada upaya: peningkatan pendapatan, pengurangan biaya atau peningkatan produktivitas, dan utilisasi aset perusahaan.

\section{Metode Penelitian}

\subsection{Rancangan Penelitian}

Penelitian ini merupakan penelitian deskriptif berdasarkan observasi yang dilakukan pada lima perusahaan jasa di Indonesia.

\subsection{Perusahaan Terpilih}

Peneliti menetapkan perusahaan jasa sebagai subjek penelitian dengan pertimbangan bahwa perusahaan jasa memiliki ruang lingkup operasi yang paling sederhana dibandingkan dengan perusahaan dagang dan manufaktur. Pada tahap awal dalam penelitian mengenai penerapan balanced scorecard maka akan dilakukan pada tiga perusahaan jasa terpilih, yaitu PT Fast Food Indonesia, PT Graha Layar Prima dan PT Kristamedia Pratama.

\subsection{Pengumpulan Data}

Teknik yang digunakan penulis dalam penelitian ini adalah sebagai berikut:

a. Pengumpulan data melalui penilaian kepustakaan (Library Research) dilakukan dengan mengkaji buku, situs web, majalah dan jurnal ilmiah untuk memperoleh landasan teoritis yang kuat dan menyeluruh tentang Balanced Scorecard.

b. Telaah dokumen yaitu mengumpulkan informasi data dengan mempelajari referensi, laporan keuangan perusahaan, maupun yang berkaitan dengan masalah yang diteliti.

c. Penelitian lapangan yaitu mengumpulkan data primer, dengan cara mendatangi perusahaan.

\subsection{Metode Analisis Data}

Data dianalisis melalui beberapa tahap:

a. Penetapan target dan KPI untuk tiap-tiap perusahaan.

b. Inventarisasi data yang terkait dengan pengukuran keempat perspektif.

c. Melakukan penghitungan untuk setiap item dalam kolom balanced scorecard. 
d. Membandingkan standar dengan realisasi pencapaian kinerja.

\section{Hasil dan Pembahasan}

\subsection{PT Fast Food Indonesia}

PT Fast Food Indonesia, Tbk bergerak di bidang jasa dalam penawaran makanan cepat saji. PT Fast Food Indonesia, Tbk merupakan pemegang hak waralaba tunggal untuk merek KFC di Indonesia. PT Fast Food Indonesia, Tbk (KFC) berkantor pusat dan berlokasi di Gedung Galael, Jl. Let. Jend. M.T. Haryono Kav. 7, Jakarta. Untuk memperoleh data primer maka penelitian dilakukan di cabang KFC yang berlokasi di BSD Square, Serpong.

\subsubsection{Perspektif Keuangan}

Target yang diharapkan pada perspektif keuangan di KFC cabang BSD Square adalah sebesar 4\% untuk pertumbuhan penjualan (sales growth) disetiap tahunnya dan target penjualan (sales target) selama tahun 2014 sebesar Rp. 10.241.000.000.

\subsubsection{Target Perspektif Pelanggan}

Perspektif pelanggan memiliki dua sasaran strategik, yaitu customer core measurement, yang terbagi dalam dua kategori diantaranya market share dan customer satis-faction, dan customer value proposition, yang tebagi dalam dua kategori juga diantaranya pro-duct/service attributes dan customer relationship.

Tabel 4.1

Hasil Pengamatan Lapangan Waktu Penyelesaian Pesanan (Dalam Detik)

\begin{tabular}{|c|c|c|c|c|}
\hline & $\begin{array}{c}\text { Waktu } \\
\text { pengolahan }\end{array}$ & $\begin{array}{c}\text { waktu } \\
\text { pemesan } \\
\text { produk }\end{array}$ & $\begin{array}{c}\text { waktu } \\
\text { penyiapan } \\
\text { produk }\end{array}$ & $\begin{array}{l}\text { waktu pembayaran } \\
\text { dan penyampaian }\end{array}$ \\
\hline & 900 & 18 & 67 & 8 \\
\hline & & 60 & 600 & 10 \\
\hline & & 48 & 144 & 11 \\
\hline & & 20 & 65 & 12 \\
\hline & & 33 & 75 & 16 \\
\hline $\begin{array}{c}\text { Rata - } \\
\text { rata }\end{array}$ & 900 & 35,8 & 190,2 & 11,4 \\
\hline
\end{tabular}


Perspektif proses bisnis internal memiliki tolok ukur, yaitu penyelesaian pesanan yang tergolong dalam proses operasi dengan meng-gunakan rumus Manufacturing Cycle Efficiency (MCE).

\subsubsection{Target Prespektif Pem- belajaran dan Pertumbuhan}

Perspektif pembelajaran dan pertumbuhan memiliki sasaran strategik, yaitu kemampuan pekerja, yaitu tingkat kepuasan karyawan berdasarkan hubungan kerjasama, pelatihan, penghargaan atas prestasi kerja, gaji dan fasilitas yang disediakan.

Tabel 4.2

Hasil Pengukuran Kinerja PT Fast Food Indonesia, Tbk (KFC) Cabang BSD Square

\begin{tabular}{|c|c|c|c|c|c|}
\hline Balanced Scorecard & $\begin{array}{l}\text { Realisasi } \\
\text { (a) }\end{array}$ & $\begin{array}{l}\text { Target } \\
\text { (b) }\end{array}$ & $\begin{array}{l}\text { Pencapaian } \\
\text { Target \% } \\
\text { (a: b) }\end{array}$ & $\begin{array}{l}\text { Bobot } \\
\text { (c) }\end{array}$ & $\begin{array}{l}\text { Skor } \\
((\mathbf{a}: \mathbf{b}) \mathrm{x} \\
\text { c) }\end{array}$ \\
\hline \multicolumn{6}{|l|}{ Perspektif Keuangan } \\
\hline $\begin{array}{l}\text { Pertumbuhan Penjualan } \\
\text { (Sales Growth) }\end{array}$ & $4,57 \%$ & $4 \%$ & $114,25 \%$ & $12,5 \%$ & $14,28 \%$ \\
\hline Pencapaian Target & $\begin{array}{c}2012: \\
\text { Pn }\end{array}$ & Rp. & $103,37 \%$ & $12,5 \%$ & $12,92 \%$ \\
\hline Penjualan & Rp. 10.586.605.350,- & 10.241.000.000,- & & $25 \%$ & $27,20 \%$ \\
\hline $\begin{array}{l}\text { Perspektif Pelanggan } \\
\text { Market Share }\end{array}$ & $\begin{array}{c}\text { 2012: } \\
\text { 233.320 customers }\end{array}$ & 180.000 customers & $129,62 \%$ & $6,25 \%$ & $8,10 \%$ \\
\hline Customer Satisfaction & 3,69 & 5 & $73,80 \%$ & $6,25 \%$ & $4,61 \%$ \\
\hline $\begin{array}{l}\text { Product/Service } \\
\text { Attributes }\end{array}$ & 3,57 & 5 & $71,40 \%$ & $6,25 \%$ & $4,46 \%$ \\
\hline Customer Relationship & 3,50 & 5 & $70,00 \%$ & $\begin{array}{c}6,25 \% \\
25 \%\end{array}$ & $\begin{array}{r}4,38 \% \\
\mathbf{2 1 , 5 5 \%}\end{array}$ \\
\hline \multicolumn{6}{|l|}{ Bisnis Internal } \\
\hline Penyelesaian Pesanan & 0,7912 & 1 & $79,12 \%$ & $\begin{array}{l}25 \% \\
25 \%\end{array}$ & $\begin{array}{l}19,78 \% \\
\mathbf{1 9 , 7 8 \%}\end{array}$ \\
\hline \multicolumn{6}{|c|}{$\begin{array}{l}\text { Perspektif } \\
\text { Pembelajaran } \\
\text { Pertumbuhan }\end{array}$} \\
\hline \multicolumn{6}{|c|}{ Tingkat Kepuasan Pelanggan berdasarkan : } \\
\hline Hubungan Kerjasama & 3,86 & 5 & $77,20 \%$ & $5 \%$ & $3,86 \%$ \\
\hline $\begin{array}{ll}\text { Pelatihan } & \text { yang } \\
\text { Diberikan } & \end{array}$ & 4,00 & 5 & $80,00 \%$ & $5 \%$ & $4,00 \%$ \\
\hline $\begin{array}{l}\text { Penghargaan } \\
\text { Prestasi Kerja }\end{array}$ & 3,93 & 5 & $78,60 \%$ & $5 \%$ & $3,93 \%$ \\
\hline Gaji & 3,68 & 5 & $73,60 \%$ & $5 \%$ & $3,68 \%$ \\
\hline Fasilitas & 4,00 & 5 & $80,00 \%$ & $5 \%$ & $4,00 \%$ \\
\hline Disediakan & & & & $25 \%$ & $19,47 \%$ \\
\hline & Total Skor $B$ & nced Scorecard & & & $88,00 \%$ \\
\hline
\end{tabular}

Perspektif keuangan memberikan kontribusi skor sebesar $27,20 \%$, yang berasal dari pertumbuhan penjualan (sales growth) sebesar 14,28\%, 
dimana dalam hal tersebut $\mathrm{KFC}$ cabang BSD Square telah melebihi target. Target yang ditentukan perusahaan sebesar $4 \%$ tetapi perusahaan dapat menembus hingga $4,57 \%$. Sedangkan, pencapaian target penjualan di tahun 2014 dimana perusahaan dapat memberikan kontribusi sebesar 12,29\% karena berhasil mencapai target yang telah ditentukan. Secara keseluruhan dari skor tersebut maka perspektif keuangan dinilai telah berhasil dalam mencapai target.

Perspektif pelanggan memberikan kontribusi skor sebesar 21,55\%. Terlihat dari market share pada tahun 2014 sebesar 8,10\%. Dalam hal ini terlihat bahwa jumlah customer telah mampu melampaui jumlah customer yang telah ditargetkan. Sedangkan untuk customer satisfaction, product/ service attributes, dan customer relationship yang dihitung berdasarkan hasil survei melalui kuesioner yang memberikan kontribusi masing-masing sebesar $4,61 \%$, 4,46\%, dan 4,38\%. Maka dapat disimpulkan bahwa dalam hal ini pencapaian target belum sempurna. Secara keseluruhan dari skor tersebut maka perspektif pelanggan dinilai belum berhasil dalam mencapai target. Hal ini terjadi karena dibagian kategori yang berkaitan langsung dengan para pelanggan, seperti customer satisfaction, product/service attri-butes, dan customer relationship ini masih belum sesuai dengan apa yang diinginkan sebagian dari para customer-nya. Disini para pelanggan masih belum merasakan titik kepuasan maksimal atas kinerja KFC BSD Square dan ini terlihat dari hasil perhitungan kuesioner yang dilakukan penulis. Oleh karena itu, sebaiknya KFC BSD Square ini lebih memperhatikan kemauan para pelanggannya agar kepuasan atas kinerjanya mendapatkan penilaian yang maksimal. Cara yang bisa diaplikasikan di KFC BSD Square agar memaksimalkan kepuasan para pelanggan diantaranya adalah :

a. Melatih para karyawan- karyawati untuk bisa lebih cekatan dalam memberikan pelayanan kepada customer dengan cara memperbanyak staff yang berada di front office untuk membantu menghidangkan pesanan pelanggan agar lebih cepat disertai dengan senyuman ramah tamah. 
KFC BSD Square bisa menyediakan kotak penilaian untuk setiap meja kasir atas nama kasir yang bersangkutan pada saat itu, dengan cara memberikan lembaran sticker smile yang dapat dimasukkan ke kotak penilaian dengan tiga kategori (sangat puas, puas, tidak puas) oleh para pelanggan sesuai dengan kepuasan si pelanggan, apakah si pelanggan merasa puas atas pelayanan yang diberikan dan penuh senyuman.

b. KFC BSD Square juga harus lebih memperhatikan kebersihan toilet dan wastafel dengan cara selalu membersihkan toilet disetiap waktu apalagi ketika pengunjung datang di peak hours dan memperhatikan kegunaan wastafel, dimana mengecek dan memperbaiki wastafel yang rusak sehingga para pelanggan tidak harus turun ke lantai dasar atau sebaliknya hanya untuk mencuci tangan setelah makan.

Perspektif proses bisnis internal memberikan kontribusi skor sebesar 19,78\%. Hal ini terlihat dari penyelesaian pesanan yang hanya dapat mencapai target sebesar $79,12 \%$ dari target yang telah ditetapkan. Secara keseluruhan dari skor tersebut maka perspektif proses bisnis internal dinilai belum berhasil dalam mencapai target. Hal ini terjadi karena masih adanya tingkat ketidak efisiensian dalam melakukan proses produksi sampai produk itu berada di tangan pelanggan. Dari adanya ketidak efisiensi-an itu munculah sesuatu yang tidak bernilai tambah bagi si perusahaan. Oleh karena itu, untuk meminimalkan kontribusi yang tidak bernilai tambah ini, KFC BSD Square harus melatih para karyawan karyawati agar lebih cekatan dalam melakukan proses produksi sampai produk tersebut berada di tangan pelanggan dalam waktu yang cukup singkat sehingga mengurangi waktu ketidak efisiensi-annya. Cara yang dapat diaplikasikan adalahn KFC BSD Square bisa saja memberikan batas waktu disetiap prosesnya, terutama dalam waktu penyajian pesanan ke pelanggan yang masih terbilang lama, dengan cara menyediakan jam pasir di setiap meja kasir, dimana crew chasier ini akan memulai waktu penyajiannya sebelum jam pasir itu habis. Cara yang seperti itu bisa meng-efektifkan 
waktu yang ada, sehingga mendorong para staff agar lebih cekatan.

Perspektif pembelajaran dan pertumbuhan memberikan kontribusi skor sebesar 19,47\%. Terlihat dari tingkat kepuasan karyawan karyawati yang tidak dapat mencapai targetnya. Dimana tingkat kepuasan berdasarkan hubungan kerjasama, pelatihan yang diberikan, penghargaan atas prestasi kerja, gaji, dan fasilitas yang disediakan memberikan kontribusi yang berbeda-beda diantaranya secara berurutan yaitu sebesar 3,86\%, $4,00 \%, 3,93 \%, 3,68 \%$ dan $4,00 \%$. Jika dilihat hasil pencapaian target pada masing-masingya adalah $87,20 \%$ untuk tingkat kepuasan berdasarkan hubungan kerjasama, $80,00 \%$ untuk pelatihan yang diberikan, $\quad 78,60 \%$ untuk penghargaan atas prestasi kerja, $73,60 \%$ untuk gaji dan sebesar $80,00 \%$ untuk fasilitas yang disediakan. Secara keseluruhan dari skor tersebut maka perspektif pembelajaran dan pertumbuhan dinilai belum berhasil dalam mencapai target. Hal ini terjadi karena kepuasan para karyawan - karyawati di KFC BSD Square ini masih belum mencapai tingkat kepuasan yang maksimal, terutama dilihat dari gaji dan hubungan kerjasama para karyawan- karyawati-nya. Bukan hanya itu saja tetapi, KFC BSD Square ini juga masih kurang memberikan perhatiaannya kepada para karyawan - karyawati baik dari segi pelatihan yang diberikan, penghargaan atas prestasi kerja serta fasilitas yang disediakan untuk para karyawannya. Tingkat kepuasan karyawan - karyawati KFC BSD Square yang tidak sesuai target ini menyebabkan penilaian kinerja atas perspektif pembelajaran dan pertumbuhan ini belum mencapai target secara keseluruhan. Oleh karena itu, tindakan selanjutnya KFC BSD Square ini harus lebih memperhatikan kesejahteraan para karyawan - karyawati nya baik berdasarkan hubungan kerja, pelatihan yang diberikan, penghargaan atas prestasi kerja, gaji, dan fasilitas yang disediakan sehingga tingkat kepuasan para karyawan karyawati pun akan lebih baik dari yang sebelumnya. Cara yang dapat diaplikasikan oleh KFC BSD Square sesuai dengan harapan untuk 
memenuhi kepuasan para karyawan karyawati adalah :

a. Menjaga komunikasi antar rekan kerja, disini manager bisa saja melakukannya dengan cara menyelengarakan meeting bersama semua karyawan dimana setiap karyawan - karyawati boleh mengeluarkan pendapat dan boleh menanggapi pendapat tersebut satu dengan yang lainnya. Tapi dengan suasana yang tidak terlalu formal dengan adanya selingan entertaintnya (santai). Dengan cara ini bisa meningkatkan kerjasama antar rekan kerja (team) dan menjaga komunikasi antar atasan dan bawahan.

b. Lebih open mind dan menerima semua inovasi dari team member yang kemudian dapat diperbincangkan sehingga tercipta inovasi yang menjadi nilai tambah bagi KFC BSD Square

Sehubungan dengan pendekatan Balanced Scorecard dalam pengukuran kinerja manajemen pada PT Fast Food Indonesia, Tbk (KFC) cabang BSD Square ini, sebelumnya hanya terfokus pada penilaian berdasarkan dua perspektif saja, yaitu perspektif keuangan, dimana perusahaan lebih memfokuskan pada tingkat sales dan profit, serta perspektif pelanggan. Oleh karena itu, penulis mencoba untuk melengkapinya dengan melakukan penilaian kinerja berdasarkan Balanced Scorecard yang terdiri dari empat perspektif, diantaranya adalah perspektif keuangan, perspektif pelanggan, perspektif proses bisnis internal, dan perspektif pembelajaran dan pertumbuhan. Alasan penulis melengkapi penilaian kinerja KFC BSD Square ini dengan empat perspektif Balanced Scorecard dikarenakan penulis ingin mengetahui kinerja KFC BSD Square ini secara keseluruhan berdasarkan empat perspektif yang ada dan dengan menggunakan keempat perspetif tersebut hasil akhir suatu kinerja dapat dinilai secara baik dan jelas.

\subsection{PT Medium Primaniaga}

PT. Kristamedia Pratama didirikan sejak tahun 1994, dan berdomisili di Jl. Blandongan No. 28D/G, Tambora, Jakarta Barat. PT. Kristamedia Pratama bergerak di bidang jasa penyelenggara pameran dan terdaftar 
sebagai anggota Asosiasi Perusahaan Pameran Indo-nesia (ASPERAPI) sejak tahun 1994.

Nilai akhir total atau total score yang berhasil dicapai PT. Kristamedia Pratama pada tahun 2013 adalah: $(369,5 / 500) \times 100=73,90$.

Berdasarkan total score dan kriteria standar diatas, kinerja PT. Kristamedia Pratama secara keseluruhan pada tahun 2013 termasuk dalam kondisi sehat dengan kategori A. jika dilihat dari perspektif finansial, PT. Kristamedia Pratama hanya berhasil memenuhi $40 \%$ dari target karena Account Receivable Turnover, ROE, dan NPM yang diperoleh masih jauh dari target. Pada perspektif pelanggan sebesar $90 \%$ dari target berhasil dipenuhi, hal ini karena pertumbuhan pelanggan yang mencapai target dan kepuasan pelanggan yang cukup baik. Jika dilihat dari perspektif inovasi dan proses internal, PT. Kristamedia Pratama berhasil memenuhi $100 \%$ dari target. Sedangkan pada perspektif pembe-lajaran dan pertumbuhan PT. Kristamedia Pratama hanya berhasil memenuhi $67 \%$ dari target, yang disebabkan karena loyalitas dan kepuasan karyawan yang masih kurang.

\subsection{PT Graha Layar Prima}

PT Graha Layar Prima merupakan perusahaan yang memiliki merek dagang Blitzmegaplex Mall of Indonesia yang berlokasi di Kelapa gading, Jakarta Utara. Blitzmegaplex adalah bioskop pertama di Indonesia dengan konsep One Entertainment Center dengan selogan Beyond Movies. Gerai keempat berlokasi di Mall of Indonesia yang resmi dibuka pada 7 November 2008 (fasilitas yang tersedia diantaranya 10 screen dengan total 1816 kursi, velvet dan dinnind class. Café , restaurant, karaoke, lounge, digital music store, merchandise store, candy bar and snack bar).

\subsubsection{Perspektif Keuangan}

\section{a. Net Profit Margin}

Net Profit Margin pada PT. Graha Layar Prima Blitzmegaplex Mall Of Indonesia tahun 2012 sebesar (18.90\%) sedangkan di tahun 2013 Net Profit Margin menjadi (2.68\%). Hasil ini memperlihatkan bahwa terjadi peningkatan profit margin sebesar $16.22 \%$ di hasilkan dari penurunan kerugian tahun 2012 yang memiliki nilai net profit margin 
minus $18.90 \%$ kemudian di tahun 2013 menjadi minus $2.68 \%$. Rata-rata dari hasil penelitan ini sebesar $(10.79 \%)$ dan masuk dalam kriteria indikator kategori D.

\section{b. Gross Margin}

Gross Margin pada PT. Graha Layar Prima Blitzmegaplex Mall Of Indonesia tahun 2012 sebesar 59\% dan terjadi peningkatan pada tahun 2013 menjadi $62 \%$. Hal ini menandakan bahwa setiap Rp 1 penjualan yang di lakukan perusahan, maka perusahaan akan memperoleh profit kotor sebesar $59 \%$ dan peningkatan terjadi di tahun 2013 sebesar 62\%. Dari hasil penelitian tersebut di peroleh nilai rata-rata sebesar $60.5 \%$ dan masuk dalam kriteria indikator katergori A.

\section{c. Operating Margin}

Operating Margin pada PT. Graha Layar Prima Blitzmegaplex Mall Of Indonesia tahun 2012 sebesar (19.01\%) dan terjadi peningkatan pada tahun 2013 menjadi $6.20 \%$. Hal ini menandakan bahwa kegiatan operasional perusahaan semakin bertambah baik. Dari hasil penelitian tersebut di peroleh nilai rata-rata sebesar (6.405)\% dan masuk dalam kriteria indikator kategori D.

\subsubsection{Perspektif Pelanggan}

\section{a. Customer Retention}

Peningkatan Customer Retention sebesar $4.18 \%$ diperoleh dari hasil tahun 2012 sebesar $63.27 \%$ dan meningkat di tahun 2013 menjadi $67.45 \%$ dan rata-rata dari hasil diatas diperoleh $65.36 \%$ masuk dalam kriteria indikator $\mathrm{B}$ dengan interval $50 \%-75 \%$.

\section{b. Customer Satisfaction (Ke- puasan Pelanggan)}

Rata-rata keseluruhan kuesioner terhadap perhitungan 10 pertanyaan yang diberikan kepada pelanggan sebanyak 30 responden yang digunakan untuk mengukur tingkat kepuasan pelanggan Blitzmegaplex Mall Of Indonesia, di peroleh hasil 3.028 $\%$ dan masuk dalam kriteria indikator A.

\subsubsection{Perspektif Proses Bisnis Internal}

Berdasarkan hasil observasi, waktu yang diperlukan untuk antri membeli tiket, memilih film yang akan di tonton, memilih snack, proses pengambilan pengambilan snack, proses konfirmasi ulang yang disampaikan karyawan, proses pem- 
bayaran dan ucapan terima kasih memerlukan waktu rata-rata 7 menit dan masih di katergorikan puas dengan indikator B. Diasumsikan target 2012 dan 2013 sama dan realisasinya juga sama.

\subsubsection{Perspektif Pembelajaran dan Pertumbuhan}

\section{a. Produktivitas Karyawan}

Berdasarkan hasil yang diperoleh disimpulkan bahwa dari seluruh karyawan yang ada di Blitzmegaplex Mall Of Indonesia terdapat 48 karyawan produktif di tahun 2012 dan 44 karyawan produktif di tahun 2013. Sehingga diperoleh hasil $\mathrm{Rp}$ $651,719,598.5$ per orang dan terjadi peningkatan di tahun 2013 sebesar Rp 957,779,817.3 per orang. Diperoleh rata-rata sebesar $\mathrm{Rp} 804,749,707.9$ yang masih di kate-rorikan sangat baik dengan indikaor A.

\section{b. Retensi Karyawan}

Berdasarkan pada perhitungan pada tahun 2013 telah terjadi Penurunan karyawan yang resign yaitu sebesar $9.53 \%$. sedangkan rata-rata turn over karyawan diperoleh hasil $41.91 \%$ yang masih di kategorikan tidak puas dan masuk indikator D.

\section{c. Kepuasan Karyawan}

Rata-rata keseluruhan kuesioner terhadap perhitungan 10 pertanyaan yang diberikan kepada karyawan sebanyak 24 responden yang digunakan untuk mengukur tingkat kepuasan karyawan Blitzmegaplex Mall Of Indonesia, di peroleh hasil $2.893 \%$ dan masuk kedalam kriteria indikator B.

Kesimpulan yang diperoleh adalah perusahaan dengan nilai Total Score $69.78 \%$ termasuk dalam kondisi cukup sehat dengan kategori A.

PT. Graha Layar Prima Blitzmegaplex Mall Of Indonesia telah optimal dalam memberikan kepuasan kepada pelanggannya terlihat dari hasil kuesioner dengan menggunakan pengukuran skor indikator di peroleh hasil $25 \%$ dan masuk dalam kategori A dengan interval $22.5 \%$ - 30\%. Dan dari hasil tersebut dapat disimpulkan bahwa pelanggan merasa puas akan pelayanan yang Blitzmegaplex Mall Of Indonesia berikan.

Dalam perspektif keuangan PT. Graha Layar Prima Blitzmegaplex Mall Of Indonesia dalam mengatur segala bentuk pendapatan dan 
pengelolaan keuangan sudah mencapai tingkat yang baik dilihat dari hasil yang diperolehnya mengalami kenaikan dari tahun 2012 ke tahun 2013. Dengan adanya pengukuran Balanced Scorecard ini diharapkan perusahaan dapat mencapai pendapatan yang maksimal karena dengan pengukuran ini perusahan memiliki strategi dalam meminimalisir biaya-biaya yang dikeluarkan perusahaan.

Dalam perspektif proses bisnis internal PT. Graha Layar Prima Blitzmgeaplex Mall of Indonesia sudah membuktikan dengan inovasi yang dilakukan demi tercapainya target revenue di lihat dari waktu transaksi penjualan yang dilakukan di Blitzmegaplex Mall Of Indonesia.

Dalam perspektif pembelajaran dan pertumbuhan PT. Graha Layar Prima Blitzmegaplex Mall Of Indonesia sudah membuktikan telah memberikan kepuasan kepada karyawannya dalam hal kenyamanan didalam bekerja, benefit yang diperoleh setiap karyawan, jenjang karir, dsb. Sehingga dapat mengurangi jumlah karyawan yang keluar, dilihat dari hasil pengukuran labour turn over telah terjadi penurunan jumlah karyawan yang keluar sebesar 9.53\% dari tahun 2012 ke tahun 2013. Dengan hal ini kenyamanan yang dimiliki setiap karyawan akan berdampak baik bagi perusahaan karena dapat mengerahkan seluruh kemampuan karyawan agar memiliki kontribusi lebih terhadap perusahaan. Dengan menerapkan pengukuran kinerja Balanced Scorecard maka perusahaan dapat mengukur secara menyeluruh terhadap hal-hal yang berhubungan dengan operasional perusahaan. Dari hasil yang diperoleh penulis, perusahaan dapat lebih tepat dalam mengambil keputusan untuk masa yang akan datang karena metode Balanced Scorecard mengukur dari segala sudut pandang tidak hanya dari segi keuangan saja, tetapi dari perspektif pelanggan, perspektif proses bisnis internal dari hasil revenue yang di hasilnya sangat membantu peru-sahaan dalam mencapai tujuannya dan dari perspektif pembelajaran dan pertumbuhan yang mengukur kepuasan karyawan, jadi bukan hanya mengukur dari segi keuangannya saja.

\section{Simpulan dan Saran}




\subsection{Simpulan}

Dari hasil analisis yang telah dilakukan, penelitian ini memberikan hasil sebagai berikut.

a. Ketiga perusahaan memiliki pendekatan Balanced Scorecard yang agak berbeda, namun tetap menggunakan empat perspektif yang sama.

b. Penetapan bobot dan skor ditentukan sendiri oleh perusahaan dengan mempertimbangkan target yang hendak dicapai untuk tiap-tiap perspektif.

c. Indikator yang digunakan untuk tiap-tiap perspektif juga bervariasi, tergantung pada target yang hendak dicapai, dan jenis indikator juga dapat berbedabeda.

d. Ketiga perusahaan menghasilkan nilai Balanced Scorecard yang baik, yang menggambarkan bahwa kinerja keuangan dan non keuangan dapat berjalan dengan selaras dan berimbang untuk mencapai tujuan yang telah ditetapkan.

\subsection{Saran}

Bagi perusahaan yang saat ini sedang mempertimbangkan untuk menggunakan Balanced Scorecard, dapat mengadaptasi salah salah satu contoh dari ketiga perusahaan yang telah dianalis. Perusahaan dapat melakukan adaptasi sesuai dengan kondisi yang dihadapi. 


\section{Daftar Pustaka}

Anthony, Robert N. dan Govindarajan, Vijay (2009). Sistem Pengendalian Manajemen. Salemba Empat, Jakarta.

Gaspersz, Vincent (2013), All-in-one 150 Key Performance Indicators and Balanced Scorecard, Malcom Baldrige, Leans Six Sigma Suplly Chain Management, Tri-Al-Bros Publishing, Jakarta.

Hansen, Don. R., Maryanne M. Mowen, (2009a), Akuntansi Manajemen, Edisi 8, Buku 1, Salemba Empat, Jakarta.

Hansen, Don. R., Maryanne M. Mowen, (2009b), Akuntansi Manajemen, Edisi 8, Buku 2, Salemba Empat, Jakarta.

Luis, Suwardi dan Biromo (2013), Step by Step in Cascading Balanced Scorecard to Functional Scorecards, PT.
Gramedia Pustaka Utama, Jakarta.

Mahmudi (2013), Manajemen Kinerja Sektor Publik, Edisi 2, Sekolah Tinggi Ilmu Manajemen YKPN, Yogyakarta.

Rangkuti, Freddy (2013), SWOT Balanced Scorecard, Gramedia, Jakarta.

Reeve, James M., (2009), Pengantar Akuntansi Adaptasi Indonesia, Buku 1, Salemba Empat, Jakarta.

Suprayitno, Eddy (2011), Perspektif Balanced Scorecard, diakses dari

http://ekonomi.kompasiana.c om, diunduh 3 Oktober 2015.

Wibowo, (2013), Manajemen Kinerja, Edisi 3, Cetakan 6, PT Rajagrafindo Persada, Jakarta. 


\section{Lampiran}

Tabel 4.3

BOBOT DAN BOBOT INDIKATOR 2012

\begin{tabular}{|r|l|l|c|c|c|}
\hline \multicolumn{1}{|c|}{ Perspektif } & \multicolumn{1}{|c|}{ KPI } & $\begin{array}{c}\text { Jumlah } \\
\text { Indikator }\end{array}$ & Bobot & $\begin{array}{c}\text { Bobot } \\
\text { Indikator }\end{array}$ \\
\hline 1 & $\begin{array}{l}\text { Finansial } \\
3 \text { butir }\end{array}$ & $\begin{array}{l}\text { Account Receivable Turnover } \\
\text { Return on Equity } \\
\text { Net Profit Margin }\end{array}$ & 3 & 24 & 8 \\
\hline 2 & $\begin{array}{l}\text { Pelanggan } \\
2 \text { butir }\end{array}$ & $\begin{array}{l}\text { Customer Growth Rate } \\
\text { Customer Satisfaction Index }\end{array}$ & 2 & 27 & 13.5 \\
\hline 3 & $\begin{array}{l}\text { Inovasi dan Proses Internal } \\
2 \text { butir }\end{array}$ & $\begin{array}{l}\text { Penambahan Jumlah Pameran } \\
\text { Penambahan Luas Area Pameran }\end{array}$ & 2 & 22 & 11 \\
\hline 4 & $\begin{array}{l}\text { Pembelajaran dan Pertumbuhan } \\
3 \text { butir }\end{array}$ & $\begin{array}{l}\text { Revenue per Employee } \\
\text { Average Employee Tenure } \\
\text { Employee Satisfaction Index }\end{array}$ & 3 & 27 & 9 \\
\hline \multicolumn{1}{|c|}{ TOTAL } & \multicolumn{100}{|c|}{} & \\
\hline
\end{tabular}

Tabel 4.4

SKOR TERTIMBANG MAKSIMUM TAHUN 2012

\begin{tabular}{|l|c|c|c|c|}
\hline \multicolumn{1}{|c|}{ Perspektif } & $\begin{array}{c}\text { Jumlah } \\
\text { Indikator }\end{array}$ & $\begin{array}{c}\text { Skor Indikator } \\
\text { Maks }\end{array}$ & $\begin{array}{c}\text { Bobot } \\
\text { Indikator }\end{array}$ & $\begin{array}{c}\text { Skor Tertimbang } \\
\text { Maks }\end{array}$ \\
\hline Finansial & 3 & 5 & 8 & 120 \\
Pelanggan & 2 & 5 & 13.5 & 135 \\
Inovasi dan Proses Internal & 2 & 5 & 11 & 110 \\
Pembelajaran dan Pertumbuhan & 3 & 5 & 9 & 135 \\
\hline TOTAL & & & & $\mathbf{5 0 0}$ \\
\hline
\end{tabular}


Tabel 4.5

JUMLAH SKOR INDIKATOR TAHUN 2012

\begin{tabular}{|c|c|c|c|}
\hline Perspektif & KPI & Nilai & Skor Indikator \\
\hline \multirow[t]{4}{*}{ Finansial } & Account Receivable Turnover & $\mathrm{C}$ & 3 \\
\hline & Return on Equity & $\mathrm{C}$ & 3 \\
\hline & Net Profit Margin & $\mathrm{D}$ & 2 \\
\hline & \begin{tabular}{|r|} 
TOTAL \\
\end{tabular} & & 8 \\
\hline \multirow[t]{3}{*}{ Pelanggan } & Customer Growth Rate & $\mathrm{C}$ & 3 \\
\hline & Customer Satisfaction Index & B & 4 \\
\hline & \begin{tabular}{|c|} 
TOTAL \\
\end{tabular} & & 7 \\
\hline \multirow[t]{3}{*}{ Inovasi dan Proses Internal } & Penambahan Jumlah Pameran & $\mathrm{C}$ & 3 \\
\hline & Penambahan Luas Area Pameran & $\mathrm{C}$ & 3 \\
\hline & \begin{tabular}{|c|} 
TOTAL \\
\end{tabular} & & 6 \\
\hline \multirow[t]{4}{*}{ Pembelajaran dan Pertumbuhan } & Revenue per Employee & B & 4 \\
\hline & Average Employee Tenure & B & 4 \\
\hline & Employee Satisfaction Index & $\mathrm{C}$ & 3 \\
\hline & \begin{tabular}{|l} 
TOTAL \\
\end{tabular} & & 11 \\
\hline
\end{tabular}

Tabel 4.6

NILAI AKHIR PER KOMPONEN TAHUN 2012

\begin{tabular}{|l|c|c|c|}
\hline \multicolumn{1}{|c|}{ Perspektif } & $\begin{array}{c}\text { Skor Tertimbang } \\
\text { Maksimum }\end{array}$ & $\begin{array}{c}\text { Skor } \\
\text { Tertimbang }\end{array}$ & $\begin{array}{c}\text { Nilai Akhir } \\
\text { Komponen }\end{array}$ \\
\hline Finansial & 120 & 64 & $53 \%$ \\
Pelanggan & 135 & 94.5 & $70 \%$ \\
Inovasi dan Proses Internal & 110 & 66 & $60 \%$ \\
\hline Pembelajaran dan Pertumbuhan & 135 & 99 & $73 \%$ \\
\hline
\end{tabular}

Tabel 4.7

NILAI AKHIR TOTAL ATAU TOTAL SCORE TAHUN 2012

\begin{tabular}{|l|c|c|c|}
\hline \multicolumn{1}{|c|}{ Perspektif } & $\begin{array}{c}\text { Jumlah Skor } \\
\text { Indikator }\end{array}$ & $\begin{array}{c}\text { Bobot } \\
\text { Indikator }\end{array}$ & $\begin{array}{c}\text { Skor } \\
\text { Tertimbang }\end{array}$ \\
\hline Finansial & 8 & 8 & 64 \\
Pelanggan & 7 & 13.5 & 94.5 \\
Inovasi dan Proses Internal & 6 & 11 & 66 \\
Pembelajaran dan Pertumbuhan & 11 & 9 & 99 \\
\hline \multicolumn{2}{|c|}{ Jumlah Skor Tertimbang } & $\mathbf{3 2 3 . 5}$ \\
\hline
\end{tabular}


Tabel 4.8

KRITERIA STANDAR TAHUN 2012 dan 2013

\begin{tabular}{|l|c|c|}
\hline \multicolumn{1}{|c|}{ Kondisi } & Kategori & Total Score \\
\hline SEHAT & AAA & $\geq 95$ \\
& AA & $80<\mathrm{TS}<95$ \\
& A & $65<\mathrm{TS}<80$ \\
\hline KURANG SEHAT & BBB & $50<\mathrm{TS}<65$ \\
& $\mathrm{BB}$ & $40<\mathrm{TS}<50$ \\
& $\mathrm{~B}$ & $30<\mathrm{TS}<40$ \\
\hline TIDAK SEHAT & $\mathrm{CCC}$ & $20<\mathrm{TS}<30$ \\
& $\mathrm{CC}$ & $10<\mathrm{TS}<20$ \\
& $\mathrm{C}$ & $\mathrm{TS}<10$ \\
\hline
\end{tabular}

Tabel 4.9

BOBOT DAN BOBOT INDIKATOR TAHUN 2013

\begin{tabular}{|r|l|l|c|c|c|}
\hline \multicolumn{1}{|c|}{ Perspektif } & \multicolumn{1}{|c|}{ KPI } & $\begin{array}{c}\text { Jumlah } \\
\text { Indikator }\end{array}$ & Bobot & $\begin{array}{c}\text { Bobot } \\
\text { Indikator }\end{array}$ \\
\hline 1 & Finansial \\
3 butir & $\begin{array}{l}\text { Account Receivable Turnover } \\
\text { Return on Equity } \\
\text { Net Profit Margin }\end{array}$ & 3 & 24 & 8 \\
\hline 2 & $\begin{array}{l}\text { Pelanggan } \\
2 \text { butir }\end{array}$ & $\begin{array}{l}\text { Customer Growth Rate } \\
\text { Customer Satisfaction Index }\end{array}$ & 2 & 27 & 13,5 \\
\hline 3 Inovasi dan Proses Internal \\
2 butir & $\begin{array}{l}\text { Penambahan Jumlah Pameran } \\
\text { Penambahan Luas Area Pameran }\end{array}$ & 2 & 22 & 11 \\
\hline 4 & $\begin{array}{l}\text { Pembelajaran dan Pertumbuhan } \\
3 \text { butir }\end{array}$ & $\begin{array}{l}\text { Revenue per Employee } \\
\text { Average Employee Tenure } \\
\text { Employee Satisfaction Index }\end{array}$ & 3 & 27 & 9 \\
\hline & & & & 100 & \\
\hline
\end{tabular}

Tabel 4.10

SKOR TERTIMBANG MAKSIMUM TAHUN 2013

\begin{tabular}{|l|c|c|c|c|}
\hline \multicolumn{1}{|c|}{ Perspektif } & $\begin{array}{c}\text { Jumlah } \\
\text { Indikator }\end{array}$ & $\begin{array}{c}\text { Skor Indikator } \\
\text { Maks }\end{array}$ & $\begin{array}{c}\text { Bobot } \\
\text { Indikator }\end{array}$ & $\begin{array}{c}\text { Skor Tertimbang } \\
\text { Maks }\end{array}$ \\
\hline Finansial & 3 & 5 & 8 & 120 \\
Pelanggan & 2 & 5 & 13,5 & 135 \\
Inovasi dan Proses Internal & 2 & 5 & 11 & 110 \\
Pembelajaran dan Pertumbuhan & 3 & 5 & 9 & 135 \\
\hline TOTAL & & & & $\mathbf{5 0 0}$ \\
\hline
\end{tabular}


Tabel 4.11

JUMLAH SKOR INDIKATOR TAHUN 2013

\begin{tabular}{|c|c|c|c|}
\hline Perspektif & KPI & Nilai & Skor Indikator \\
\hline \multirow[t]{4}{*}{ Finansial } & Account Receivable Turnover & $\mathrm{D}$ & 2 \\
\hline & Return on Equity & $\mathrm{D}$ & 2 \\
\hline & Net Profit Margin & $\mathrm{D}$ & 2 \\
\hline & $\begin{array}{r}\text { TOTAL } \\
\end{array}$ & & 6 \\
\hline \multirow[t]{3}{*}{ Pelanggan } & Customer Growth Rate & A & 5 \\
\hline & Customer Satisfaction Index & $\mathrm{B}$ & 4 \\
\hline & \begin{tabular}{|c|} 
TOTAL \\
\end{tabular} & & 9 \\
\hline \multirow[t]{3}{*}{ Inovasi dan Proses Internal } & Penambahan Jumlah Pameran & A & 5 \\
\hline & Penambahan Luas Area Pameran & A & 5 \\
\hline & \begin{tabular}{|c} 
TOTAL \\
\end{tabular} & & 10 \\
\hline \multirow[t]{4}{*}{ Pembelajaran dan Pertumbuhan } & Revenue per Employee & $\mathrm{B}$ & 4 \\
\hline & Average Employee Tenure & $\mathrm{C}$ & 3 \\
\hline & Employee Satisfaction Index & $\mathrm{C}$ & 3 \\
\hline & \begin{tabular}{|c} 
TOTAL \\
\end{tabular} & & 10 \\
\hline
\end{tabular}

Tabel 4.12

NILAI AKHIR PER KOMPONEN TAHUN 2013

\begin{tabular}{|l|c|c|c|}
\hline \multicolumn{1}{|c|}{ Perspektif } & $\begin{array}{c}\text { Skor Tertimbang } \\
\text { Maksimum }\end{array}$ & $\begin{array}{c}\text { Skor } \\
\text { Tertimbang }\end{array}$ & $\begin{array}{c}\text { Nilai Akhir } \\
\text { Komponen }\end{array}$ \\
\hline Finansial & 120 & 48 & $40 \%$ \\
\hline Pelanggan & 135 & 121,5 & $90 \%$ \\
\hline Inovasi dan Proses Internal & 110 & 110 & $100 \%$ \\
\hline Pembelajaran dan Pertumbuhan & 135 & 90 & $67 \%$ \\
\hline
\end{tabular}

Tabel 4.13

NILAI AKHIR TOTAL ATAU TOTAL SCORE TAHUN 2013

\begin{tabular}{|l|c|c|c|}
\hline \multicolumn{1}{|c|}{ Perspektif } & $\begin{array}{c}\text { Jumlah Skor } \\
\text { Indikator }\end{array}$ & $\begin{array}{c}\text { Bobot } \\
\text { Indikator }\end{array}$ & $\begin{array}{c}\text { Skor } \\
\text { Tertimbang }\end{array}$ \\
\hline Finansial & 6 & 8 & 48 \\
Pelanggan & 9 & 13,5 & 121,5 \\
Inovasi dan Proses Internal & 10 & 11 & 110 \\
Pembelajaran dan Pertumbuhan & 10 & 9 & 90 \\
\hline \multicolumn{2}{|c|}{ Jumlah Skor Tertimbang } & $\mathbf{3 6 9 , 5}$ \\
\hline
\end{tabular}

